\title{
Serum prolidase enzyme activity as a diagnostic marker for acute ischemic stroke.
}

\author{
Abdulkadir Tunç ${ }^{*}$, Dilcan Kotan², Mehmet Akdoğan ${ }^{3}$, Saadet Sayan ${ }^{3}$ \\ ${ }^{1}$ Department of Neurology, Bezmialem Vakif University, Istanbul, Turkey \\ ${ }^{2}$ Department of Neurology, Sakarya University, Sakarya, Turkey \\ ${ }^{3}$ Department of Medical Biochemistry, Sakarya University, Sakarya, Turkey
}

\begin{abstract}
Objective: We aimed to investigate whether Serum Prolidase Activity (SPA) levels could be used as a potential diagnostic and/or prognostic biomarker in Acute Ischemic Stroke (AIS) patients or not. Materials and methods: SPA levels were prospectively evaluated in 37 patients aged between 20 and 85 y who were admitted within $24 \mathrm{~h}$ of the onset of AIS. The control group included 37 healthy volunteers of similar age without any disease.

Results: In AIS patients, mean SPA was significantly higher compared to healthy controls $(1331 \pm 399$ $\mathrm{pg} / \mathrm{ml}$ vs. $1169 \pm 221 \mathrm{pg} / \mathrm{ml}$, respectively; $\mathrm{p}=0.035$ ). SPA was not correlated with age, gender, hypertension, diabetes, total cholesterol, triglycerides, high-density lipoprotein, low-density lipoprotein, hemoglobin, c-reactive protein, or hemoglobin A1c levels ( $p>0.05$ for all comparisons). However, patients with new diagnostic atrial fibrillation had higher levels of prolidase acitvity than the others $(1647 \pm 403$ $\mathrm{pg} / \mathrm{ml} v s .1270 \pm 384 \mathrm{pg} / \mathrm{ml}, \mathrm{p}=0.032$ ). SPA levels were also uncorrelated with National Institutes of Health Stroke Scale, infarct volume, Trial of Org 10172 and the Oxfordshire Community Stroke Project classifications, and duration of hospitalization ( $p>0.05$, for all comparisons).

Conclusions: Increased levels of serum prolidase enzyme activity may be an independent predictor of AIS and may contribute to stroke pathophysiology. However, further studies with larger populations are needed to reveal the role of SPA in AIS.
\end{abstract}

Keywords: Acute ischemic stroke, Serum prolidase activity, Prognosis, Diagnosis, Biomarker.

Accepted on December 14, 2017

\section{Introduction}

Stroke causes significant burdens for human health and life, including high morbidity, mortality, and disability [1]. Ischemic stroke constitutes about $80-85 \%$ of all stroke cases and is caused by the interruption of cerebral blood flow due to a blood clot [2]. A complex cascade of metabolic events begins with brain ischemia. Oxygen free radicals and related reactive chemical species leading to oxidative stress cause the damage that occurs after permanent ischemia especially in the penumbral region of infarcts [3].

Collagen is the basis for the connective tissue structures involved in inflammation, wound healing, cell movement, trophoblast implantation, and fetal development [4]. Collagen types 1 and 3 fibers are important for the arterial wall strength [5]. Consequently, any vascular damage will affect the collagen cycle. Prolidase, which is a cytosolic exopeptidase and a member of the Matrix Metalloproteinase (MMP) family, cleaves iminopeptides from carboxy-terminal ends of proline or hydroxyproline and is actively involved in collagen metabolism [6]. An increase in collagen turnover is known to be correlated with increased prolidase enzyme activity [7]. Prolidase enzyme activity was found in various organs, such as the heart, brain, thymus, kidney, lung, pancreas, and spleen, and in plasma, leukocytes, erythrocytes, and dermal fibroblasts [8].

MMPs are belonging to a zinc-dependent proteolytic enzymes family and degrade the Extracellular Matrix (ECM) that results in an obstruction of distal vasculature and makes the plaque unstable [9]. Prolidase catalyses the terminal step of the degradation [10]. It has been shown that brain MMP activity is correlated with nitrative/oxidative stress and increases during reperfusion [11]. Furthermore, in stroke patients, elevated serum MMP levels have been reported [12].

Biomarkers that predict the outcome and occurrence of ischemic stroke are critically important for prevention and treatment [13]. However, Serum Prolidase Activity (SPA) has not been previously assessed in Acute Ischemic Stroke (AIS) patients to our knowledge. We hypothesized that as a result of increased oxidative stress and collagen turnover, elevated SPA levels could reflect brain tissue damage in AIS. Therefore, in 
this study, we aimed to investigate whether the SPA levels in AIS patients could be used as a potential diagnostic and/or prognostic marker or not.

\section{Materials and Methods}

This study was performed in the neurology clinic of the Sakarya Education and Research Hospital between May 2016 and May 2017. In the study, 37 patients aged between 20 and $85 \mathrm{y}$ who were admitted within $24 \mathrm{~h}$ of the onset of AIS were prospectively evaluated. The control group consisted of 37 healthy volunteers of similar age without any disease.

The study was approved by the Sakarya University Human Ethics Committee. A detailed written informed consent from each individual was obtained before participation or from a family member if necessary. Exclusion criteria were as follows: patients with heart disease (such as myocardial infarction or heart failure, chronic obstructive pulmonary disease, pulmonary embolism, pulmonary hypertension, tuberculosis, lung cancer, chronic renal failure, or current hormone replacement treatment.

\section{Data collection}

A comprehensive physical examination was performed consisting of a neurological examination, blood biochemistry and blood count tests, electrocardiography, and a posterioranterior chest X-ray for all patients. AIS patients underwent transthoracic echocardiography, multi-slice Computed Tomography (CT), and bilateral carotid-vertebral artery Doppler ultrasonography. National Institutes of Health Stroke Scale (NIHSS) scores, measured at $24 \mathrm{~h}, 48 \mathrm{~h}$, and $28 \mathrm{~d}$ after stroke, were used to determine stroke severity [14]. Infarct localization and infarct size at $24 \mathrm{~h}$ were recorded according to findings from cranial magnetic resonance imaging.

Ischemic stroke subtypes classification was done according to the Trial of Org 10172 in Acute Stroke Treatment (TOAST) criteria, as cardioembolism, large-artery atherosclerosis, small artery occlusion, stroke of other determined cause, or undetermined cause [15]. To determine the anatomical subtype of stroke, the Oxfordshire Community Stroke Project (OCSP) classification was used [16]. Multidetector CT findings taken within 24 hours were analysed. According to the size of the infarction, the subjects were divided into the groups as follows: large infarct $\left(>10 \mathrm{~cm}^{3}\right)$, middle infarct $\left(4.1-10 \mathrm{~cm}^{3}\right)$, and small infarct group $\left(\leq 4 \mathrm{~cm}^{3}\right)[16]$.

\section{Samples}

Blood samples were taken from all groups after overnight fasting. The blood was collected in non-EDTA tubes and centrifuged at $4^{\circ} \mathrm{C}$ at $3000 \mathrm{rpm}$ for $10 \mathrm{~min}$; after centrifugation, the serum was separated from the cells immediately. Serum samples for the measurement of prolidase activity and other biochemical parameters were stored at $-80^{\circ} \mathrm{C}$ until use. After thawing the samples, the measurements were performed in the same series.

\section{Prolidase assay}

The measurement method for SPA was defined by Myara et al. [17]. We used the optimized method of Ozcan et al. [18]. Prolidase activity was evaluated with a spectrophotometric method, by measuring the proline levels. Briefly, $500 \mu \mathrm{L}$ preincubation solution $(50 \mathrm{mmol} / \mathrm{L}$ Tris hydrochloride buffer at $\mathrm{pH} 7.8$, with $1 \mathrm{mmol} / \mathrm{L}$ endogenous antioxidant Glutathione (GSH), $5 \mathrm{mmol} / \mathrm{L}$ manganese(II) chloride $\left(\mathrm{MnCl}_{2}\right)$, and $0.1 \%$ Triton X-100) and $100 \mu \mathrm{L}$ serum were mixed; this mixture was then pre-incubated for $3 \mathrm{~h}$ at $37^{\circ} \mathrm{C}$. A $100-\mu \mathrm{L}$ volume of preincubation serum was added to $100 \mu \mathrm{L} 144 \mathrm{mmol} / \mathrm{L}$ Gly-Pro solution, and this mixture was incubated for $30 \mathrm{~min}$ at $37^{\circ} \mathrm{C}$. After the incubation, $1 \mathrm{ml} 0.45 \mathrm{~mol} / \mathrm{L}$ trichloroacetic acid solution was added quickly to the incubation tube, and the incubation reaction was stopped. This mixture was centrifuged at $1500 \mathrm{rpm}$ for $5 \mathrm{~min}$, and $500 \mu \mathrm{L}$ supernatant was removed. For the proline measurement, the supernatant was used by Myara et al.'s method [17], which is known as a Chinard's method's modification [19].

\section{Statistical analysis}

To evaluate distribution of variables, the Kolmogorov-Smirnov test was used. To compare the continuous parametric data, a two-independent-sample t-test was performed. The MannWhitney $\mathrm{U}$ test was used for the comparison of the continuous nonparametric data. The continuous data were introduced as the mean \pm standard deviation. Spearman's or Pearson's correlation coefficient was used for determining the relationship between variables. A p-value $<0.05$ was considered as significant. Commercial software (IBM SPSS Statistics, Version 22.0., Armonk, NY: IBM Corp.) was used to perform the analyses.

\section{Results}

The mean age of AIS patients $(n=37)$ was $66.32 \pm 9.95$, and 15 of the patients $(40.5 \%)$ were male. In the control group $(n=37)$, the mean age was $65.7 \pm 10.45$, and 16 of the patients $(43.2 \%)$ were male. The demographic data of the patients and the healthy controls were similar, and no significant differences were found in female/male ratios or age between the patients and the healthy controls ( $\mathrm{p}>0.05$; Table 1$)$.

The mean \pm SD of the total group NIHSS scores obtained on admission and at $24 \mathrm{~h}, 48 \mathrm{~h}$, and $28 \mathrm{~d}$ after stroke were $11 \pm 9$, $10.3 \pm 9,9 \pm 9.06$, and $8.6 \pm 8.8$, respectively. In AIS patients, serum prolidase activity was significantly higher compared to healthy controls $(p=0.035)$. In the ischemic stroke group, prolidase activity on admission averaged $1331 \pm 199 \mathrm{pg} / \mathrm{ml}$. Prolidase activity in the controls was $1169 \pm 221 \mathrm{pg} / \mathrm{ml}$.

Death was the primary outcome measurement. Mortality data were recorded during hospitalization. Four patients $(10.8 \%)$ died according to the data obtained during hospitalization. Cerebral herniation and brain edema were the causes of death.

SPA was not correlated with age, gender, hypertension, diabetes, total cholesterol, triglycerides, high-density 
Serum prolidase enzyme activity as a diagnostic marker for acute ischemic stroke

lipoprotein, low-density lipoprotein, hemoglobin, c-reactive protein, or hemoglobin Alc levels ( $\mathrm{p}>0.05)$. However, patients with new diagnostic atrial fibrillation had higher levels of prolidase acitvity ( $\mathrm{p}=0.032$; Table 2 ). SPA levels were also uncorrelated with NIHSS, infarct size, TOAST and OCSP classifications, and duration of hospitalization $(\mathrm{p}>0.05$; Table $3)$.

\begin{tabular}{lccc}
\hline Age (year) & $66.32 \pm 9.95$ & $65.7 \pm 10.45$ & 0.073 \\
\hline Sex & & & \\
\hline Male & $15(40.5 \%)$ & $16(43.2 \%)$ & 1.000 \\
\hline Female & $22(59.5 \%)$ & $21(56.8 \%)$ & \\
\hline
\end{tabular}

Table 1. Demographic characteristics of acute ischemic stroke

*With student's t-test, $p<0.05$ is significant patients and the control subjects.

Patient $(n=37) \quad$ Control $(n=37) \quad$ P value ${ }^{*}$

Table 2. Correlations between prolidase, and other clinical and metabolic parameters.

\begin{tabular}{|c|c|c|c|c|c|c|c|c|c|c|c|c|c|}
\hline Prolidase & Age & Sex (Male) & HT & DM & TG & $\mathrm{TC}$ & LDL & HDL & HGB & CRP & HbA1c & AF & $\mathrm{EF}$ \\
\hline $\mathrm{R}$ & 0.075 & 0.13 & 0.183 & 0.163 & 0.099 & 0.024 & 0.185 & 0.189 & 0.127 & 0.075 & 0.102 & 0.353 & 0.073 \\
\hline$P$ & 0.659 & 0.135 & 0.278 & 0.335 & 0.558 & 0.89 & 0.273 & 0.264 & 0.454 & 0.658 & 0.549 & ${ }^{*} 0.032$ & 0.67 \\
\hline \multicolumn{14}{|l|}{$\mathrm{HT}$} \\
\hline $\mathrm{R}$ & & & & 0.203 & 0.013 & 0.117 & 0.182 & 0.242 & 0.022 & 0.133 & 0.083 & 0.062 & 0.081 \\
\hline$P$ & & & & 0.228 & 0.939 & 0.489 & 0.562 & 0.635 & 0.342 & 0.73 & 0.625 & 0.713 & 0.636 \\
\hline \multicolumn{14}{|l|}{ DM } \\
\hline $\mathrm{R}$ & & & & & 0.222 & 0.212 & 0.183 & 0.143 & 0.065 & 0.148 & -0.65 & -0.92 & 0.028 \\
\hline$P$ & & & & & 0.187 & 0.209 & 0.278 & 0.31 & 0.712 & 0.162 & 0.821 & 0.587 & 0.87 \\
\hline \multicolumn{14}{|l|}{ TG } \\
\hline $\mathrm{R}$ & & & & & & 0.457 & 0.296 & -0.16 & -0.128 & 0.066 & 0.332 & -0.034 & 0.237 \\
\hline $\mathrm{P}$ & & & & & & *0.004 & 0.076 & 0.344 & 0.452 & 0.697 & ${ }^{*} 0.045$ & 0.841 & 0.159 \\
\hline \multicolumn{14}{|l|}{ TC } \\
\hline $\mathrm{R}$ & & & & & & & 0.882 & -0.47 & -0.259 & 0.058 & -0.165 & -0.065 & -0.212 \\
\hline$P$ & & & & & & & 0.062 & 0.78 & 0.121 & 0.735 & 0.329 & 0.704 & 0.209 \\
\hline \multicolumn{14}{|l|}{ LDL } \\
\hline $\mathrm{R}$ & & & & & & & & -0.133 & -0.1 & 0.1 & 0.162 & 0.096 & 0.066 \\
\hline$P$ & & & & & & & & 0.432 & 0.554 & 0.556 & 0.344 & 0.574 & 0.262 \\
\hline \multicolumn{14}{|l|}{ HDL } \\
\hline $\mathrm{R}$ & & & & & & & & & 0.185 & -0.386 & 0.112 & 0.014 & 0.056 \\
\hline$P$ & & & & & & & & & 0.274 & 0.18 & 0.534 & 0.933 & 0.712 \\
\hline \multicolumn{14}{|l|}{ HGB } \\
\hline $\mathrm{R}$ & & & & & & & & & & 0.06 & 0.057 & -0.229 & 0.212 \\
\hline$P$ & & & & & & & & & & 0.726 & 0.736 & 0.173 & 0.207 \\
\hline \multicolumn{14}{|l|}{ CRP } \\
\hline $\mathrm{R}$ & & & & & & & & & & & 0.94 & 0.391 & -0.106 \\
\hline$P$ & & & & & & & & & & & 0.569 & 0.17 & 0.533 \\
\hline \multicolumn{14}{|l|}{ HBA1C } \\
\hline $\mathrm{R}$ & & & & & & & & & & & & 0.06 & 0.141 \\
\hline
\end{tabular}




\begin{tabular}{|c|c|c|}
\hline$P$ & 0.724 & 0.406 \\
\hline \multicolumn{3}{|c|}{$\mathrm{AF}$} \\
\hline $\mathrm{R}$ & & -0.079 \\
\hline $\mathrm{P}$ & & 0.644 \\
\hline
\end{tabular}

HT: Hypertension; DM: Diabetes Mellitus; TG: Triglyceride; TC: Total Cholesterol; HDL: High-Density Lipoprotein; LDL: Low-Density Lipoprotein; HGB: Hemoglobin; CRP; C-Reactive Protein; HBA1C; Hemoglobin A1c, AF; Atrial Fibrillation. *Significant positive correlation, $p<0.05$.

Table 3. Correlations between prolidase and NIHSS, infarct volume, Toast- OCSP classifications and duration of hospitalisation.

\begin{tabular}{|c|c|}
\hline & Prolidase \\
\hline \multirow[t]{2}{*}{ NIHSS score at admission } & r: 0.169 \\
\hline & p: 0.317 \\
\hline \multirow[t]{2}{*}{ NIHSS score at $24 \mathrm{~h}$} & r: 0.203 \\
\hline & $\mathrm{p}: 0.228$ \\
\hline \multirow[t]{2}{*}{ NIHSS score at $48 \mathrm{~h}$} & r: 0.175 \\
\hline & p: 0.300 \\
\hline \multirow[t]{2}{*}{ NIHSS score at $28 \mathrm{~d}$} & $r: 0.215$ \\
\hline & p: 0.201 \\
\hline \multirow[t]{2}{*}{ Infarct volume } & r: 0.163 \\
\hline & p: 0.334 \\
\hline \multirow[t]{2}{*}{ TOAST } & r: 0.457 \\
\hline & p: 0.105 \\
\hline \multirow[t]{2}{*}{ OCSP } & r: 0.025 \\
\hline & p: 0.884 \\
\hline \multirow[t]{2}{*}{ Duration of hospitalisation } & r: 0.069 \\
\hline & p: 0.684 \\
\hline
\end{tabular}

NIHSSS; National Institutes of Health Stroke Scale; OCSP: The Oxfordshire Community Stroke Project; TOAST; Trial of Org 10172. "Significant positive correlation, $p<0.05$.

\section{Discussion}

We evaluated the activity of serum prolidase, which is a member of the MMP group, in acute ischemic stroke patients in this study. A significant increase was detected in SPA in AIS patients compared to the control group. SPA was positively correlated with the presence of atrial fibrillation.

Prolidase is an important enzyme that plays an important role in the regulation of collagen metabolism. Prolidase activity has been shown to be significantly different in a variety of diseases that are thought to involve the pathogenesis of collagen biosynthesis [20]. In some clinical trials, increased SPA has been detected in a variety of diseases, such as chronic liver diseases, various tumor types (including breast and lung cancer), bronchial asthma, fetal intrauterine growth retardation and neural tube defects, bipolar disorder, thalassemia major, and erectile dysfunction $[4,5,21,22]$.
Moreover, in various diseases characterized by chronic inflammation, it has been determined that serum prolidase enzyme activity is increased due to the deterioration of collagen [4]. Prolidase is an important type of MMP and in the degradation of the ECM, it catalyses the terminal step. The MMP group is known to be necessary for the destruction of the ECM around neurons and cerebral blood vessels [10]. This effect of MMPs causes the blood-brain barrier to open, leading to hemorrhage, brain edema, and cell death. In ischemic stroke patients, plasma MMP-9 protein levels increasing after the stroke onset and reaching a peak within $24 \mathrm{~h}$ has been reported [23].

Currently, stroke diagnosis depends on clinical examination and neuroimaging techniques [1]. The identification of effective biomarkers for early diagnosis of AIS and the establishment of biological procedures for early detection are critically needed. To our knowledge, this is the first study to investigate SPA in AIS patients.

Prolidase activity has been reported to be associated with inflammation in the fibrosis process and with oxidative stress in different diseases [6]. Inflammation and oxidative stress have important roles in the ischemic stroke pathogenesis [5,24]. Inflammation plays an important role during ischemic events and in the development of atherosclerosis. Studies have shown that inflammatory responses after stroke can exacerbate post-stroke tissue damage and affect clinical outcomes [25]. Oxidative stress is defined as an imbalance between impaired ROS production and metabolism. ROS have an important role in hemorrhagic and ischemic brain injuries. Many cell types can be negatively affected by oxidative stress and contribute to vascular pathologies, especially stroke pathophysiology [5]. Prolidase is a homodimeric enzyme that is affected by oxidative stress, and a significant relationship has been reported between oxidative stress and SPA in previous studies $[10,26]$. In our study, measured SPA levels were found to be significantly higher in AIS patients than in healthy controls. These results support the significant roles of inflammation and oxidative stress in stroke pathogenesis.

Our study showed a significant correlation between SPA levels and atrial fibrillation when the associated factors were evaluated. In a study by Rabus et al. [27], it was shown that atrial fibrillation was associated with SPA and oxidative stress in patients with mitral stenosis.

There are some limitations of our study. First, we measured SPA levels only once, so we could not evaluate the dynamic change of SPA levels at different stages of AIS. The other 
limitations are the low number of patients in our study and the fact that it is a case-control study.

We conclude that increased levels of serum prolidase enzyme activity may be an independent predictor of AIS and may contribute to stroke pathophysiology. However, further studies are required to investigate these pathways on the role of prolidase in the progression of cerebral ischemia and other vascular conditions.

\section{Competing Interests}

The authors report no conflicts of interest.

\section{References}

1. Tsai CF, Thomas B, Sudlow CL. Epidemiology of stroke and its subtypes in Chinese vs. white populations: a systematic review. Neurology 2013; 81: 264-272.

2. Qian L, Yuanshao L, Wensi H, Yulei Z, Xiaoli C, Brian W, Wanli Z, Zhengyi C, Jie X, Wenhui Z, Tieer Y, Hong W, Jincai H, Kunlin J, Bei S. Serum IL-33 is a novel diagnostic and prognostic biomarker in acute ischemic stroke. Aging Dis 2016; 7: 614-622.

3. Love S. Oxidative stress in brain ischemia. Brain Pathol 1999; 9: 119-131.

4. Sürücü HA, Aksoy N, Ozgöztas O, Sezen H, Yesilova Y, Turan E. Prolidase activity in chronic plaque psoriasis patients. Postepy Dermatol Alergol 2015; 32: 82-87.

5. Gonullu H, Aslan M, Karadas S, Kati C, Duran L, Milanlioglu A, Aydin MN, Demir H. Serum prolidase enzyme activity and oxidative stress levels in patients with acute hemorrhagic stroke. Scand J Clin Lab Invest 2014; 74: 199-205.

6. Verma AK, Raj J, Sharma V, Singh TB, Srivastava S, Srivastava R. Plasma prolidase activity and oxidative stress in patients with parkinsons disease. Parkinsons Dis 2015; 2015: 598028.

7. Palka JA, Phang JM. Prolidase activity in fibroblasts is regulated by interaction of extracellular matrix with cell surface integrin receptors. J Cell Biochem 1997; 67: 166-175.

8. Tabur S, Oguz E, Eren MA, Korkmaz H, Savas E, Aksoy N, Sabuncu T. Serum prolidase activity is associated with non-diabetic metabolic syndrome. Diabetol Metab Syndr 2014; 6: 142.

9. Hao Y, Tian S, Sun M, Zhu Y, Nie Z, Yang S. Association between matrix metalloproteinase gene polymorphisms and development of ischemic stroke. Int J Clin Exp Pathol 2015; 8: 11647-11652.

10. Tsuruda T, Costello-Boerrigter LC, Burnett JC Jr. Matrix metalloproteinases: pathways of induction by bioactive molecules. Heart Fail Rev 2004; 9: 53-61.

11. Bas DF, Topcuoglu MA, Gursoy-Ozdemir Y, Saatci I, Bodur E, Dalkara T. Plasma 3-nitrotyrosine estimates the reperfusion-induced cerebrovascular stress, whereas matrix metalloproteinases mainly resect plasma activity: a study in patients treated with thrombolysis or endovascular recanalization. J Neurochem 2012; 123: 138-147.

12. Gasche Y, Copin JC, Sugawara T, Fujimura M, Chan PH. Matrix metalloproteinase inhibition prevents oxidative stress-associated blood-brain barrier disruption after transient focal cerebral ischemia. J Cereb Blood Flow Metab 2001; 21: 1393-1400.

13. Frijns CJ, Kappelle LJ. Inflammatory cell adhesion molecules in ischemic cerebrovascular disease. Stroke 2002; 33: 2115-2122.

14. Lan MY, Wu SJ, Chang YY, Chen WH, Lai SL, Liu JS. Neurologic and non-neurologic predictors of mortality in ischemic stroke patients admitted to the intensive care unit. J Formos Med Assoc 2006; 105: 653-658.

15. Adams HP, Bendixen BH, Kappelle LJ, Biller J, Love BB, Gordon DL, Marsh EE 3rd. Classification of subtype of acute ischemic stroke. Definitions for use in a multicenter clinical trial. TOAST. Trial of Org 10172 in acute stroke treatment. Stroke 1993; 24: 35-41.

16. Bamford J, Sandercock P, Dennis M, Burn J, Warlow C. Classification and natural history of clinically identifiable subtypes of cerebral infarction. Lancet 1991; 337: 1521-1526.

17. Myara I, Charpentier C, Lemonnier A. Optimal conditions for prolidase assay by proline colorimetric determination: application to imminodipeptiduria. Clin Chim Acta 1982; 125: 193-205.

18. Ozcan O, Gultepe M, Ipcioglu OM, Bolat B, Kayadibi H. Optimization of the photometric enzyme activity assay for evaluating real activity of prolidase. Turk J Biochem 2007; 32: 12-16.

19. Chinard FP. Photometric estimation of proline and ornithine. J Biol Chem 1952; 199: 91-95.

20. Em S, Ucar D, Oktayoglu P, Bozkurt M, Caglayan M, Yildiz I, Evliyaoglu O, Nas K. Serum prolidase activity in benign joint hypermobility syndrome. BMC Musculoskelet Disord 2014; 15: 75.

21. Abraham P, Wilfred G, Ramakrishna B. Plasma prolidase may be an index of liver fibrosis in the rat. Clin Chim Acta 2000; 295: 199-202.

22. Cechowska-Pasko M, Palka J, Wojtukiewicz MZ. Enhanced prolidase activity and decreased collagen content in breast cancer tissue. Int J Exp Pathol 2006; 87: 289-296.

23. Montaner J, Alvarez-Sabin J, Molina C, Angles A, Abilleira S, Arenillas J, Monasterio J. Matrix metalloproteinase expression after human cardioembolic stroke: temporal profile and relation to neurological impairment. Stroke 2001; 32: 1759-1766.

24. Danton GH, Dietrich WD. Inflammatory mechanisms after ischemia and stroke. J Neuropathol Exp Neurol 2003; 62: 127-136.

25. Yu H, Huang Y, Chen X, Nie W, Wang Y, Jiao Y, Reed GL, $\mathrm{Gu}$ W, Chen H. High-sensitivity C-reactive protein in stroke patients - The importance in consideration of influence of multiple factors in the predictability for disease severity and death. J Clin Neurosci 2017; 36: 12-19. 
26. Aslan M, Nazligul Y, Horoz M, Bolukbas C, Bolukbas FF, Aksoy N, Celik H, Erel O. Serum prolidase activity and oxidative status in Helicobacter pylori infection. Clin Biochem 2007; 40: 37-40.

27. Rabus M, Demirbag R, Yildiz A, Tezcan O, Yilmaz R, Ocak AR, Alp M, Erel O, Aksoy N, Yakut C. Association of prolidase activity, oxidative parameters, and presence of atrial fibrillation in patients with mitral stenosis. Arch Med Res 2008; 39: 519-524.

\section{*Correspondence to}

Abdulkadir Tunç

Department of Neurology

Bezmialem Vakif University

Turkey 